\section{Effectiveness and safety of nutritional supplements in the treatment of hereditary retinal dystrophies: a systematic review}

N Brito-García1, T del Pino-Sedeño ${ }^{2,3}$ MM Trujillo-Martín 1,3,4, RM Coco ${ }^{5,6}$, E Rodríguez de la Rúa ${ }^{6,7}$, I del Cura-González ${ }^{4,8}$ and P Serrano-Aguilar 3,4,9

Fundación Canaria de Investigación Sanitaria (FUNCANIS), Islas Canarias, Spain

${ }^{2}$ Fundación Canaria para el Avance de la Biomedicina y la Biotecnología (BIOAVANCE), Universidad de La Laguna, Islas Canarias, Spain

\begin{abstract}
The hereditary retinal dystrophies (HRDs) are a group of genetically determined disorders that result in loss of the visual function. There is a lack of standard pharmacological treatments or widely accepted nutritional recommendations. The objective of this review is to summarise the scientific evidence on the effectiveness and safety of nutritional supplements for the treatment of HRDs. We conducted a scientific literature search on Medline and PreMedline, EMBASE, SCI-EXPANDED, SSCI, and The Cochrane Library up to August 2014. Experimental, quasi-experimental and controlled observational studies were selected. Eight studies were ultimately included, seven on retinitis pigmentosa (RP) and one on Best disease. Vitamin A, vitamin E, docosahexaenoic acid (DHA), lutein and $\beta$-carotene were assessed. A 15000 IU daily dose of vitamin A was reported to have shown a small protective effect on the progression of RP, as was the use of the carotenoids lutein and $\beta$-carotene. Different DHA doses has no effect on RP or Best disease. No supplement showed severe adverse effects in the selected studies although strong evidence of toxicity exists for high doses of vitamin $\mathbf{A}$ and $\beta$-carotene in certain populations. The selected studies concluded that there may be a small beneficial effect of vitamin $A$, lutein and $\beta$-carotene on the progression of RP. The limited evidence available indicates some well-designed additional studies on combined supplements strategies may achieve more robust conclusions. Moreover, the scarcity of evidence available on the treatment of HRD other than RP with nutritional supplements supports the need for further research efforts.
\end{abstract}

Eye (2017) 31, 273-285; doi:10.1038/eye.2016.286; published online 9 December 2016

\section{Introduction}

Hereditary retinal dystrophies (HRDs) are a broad group of hereditary, chronic and disabling disorders affecting the retina, which constitute an important source of visual loss on a global level. ${ }^{1}$ This category of clinically and genetically heterogeneous diseases affects photoreceptors and retinal pigment epithelium, and usually progresses over the years to severe reduction or loss of vision. ${ }^{2}$ As in other groups of rare diseases, with a low prevalence and complex management, evidence for effective treatment for HRDs is scarce, heterogeneous, and of low methodological quality.

There are currently no available treatments of proven effectiveness to slow the progression of HRDs. Among the treatments that have been proposed for the most prevalent forms such as retinitis pigmentosa $(\mathrm{RP})$ are nutritional supplements of vitamins and omega 3 fatty acids. ${ }^{3-6}$ However, the available evidence on the effectiveness of supplements on other HRDs is scarce and inconsistent, and to our knowledge it has not been reviewed to date in a comprehensive and holistic manner.

The aim of this study is to review and assess the available scientific knowledge on the efficacy and safety of nutritional supplementation treatments in the group of HRDs, supporting the hypothesis that this therapeutic strategy could be effective and safe in several of the HRDs. This of a Clinical Practice Guideline for the management of HRDs commissioned by the piece of research derives from the development
${ }^{3}$ Red de Investigación en Servicios de Salud en Enfermedades Crónicas (REDISSEC), Madrid, Spain

${ }^{4}$ Centro de Investigaciones Biomédicas de Canarias (CIBICAN), Universidad de La Laguna, Islas Canarias, Spain

${ }^{5}$ Institute of Applied Ophthalmo-Biology (IOBA) Valladolid, Spain

${ }^{6}$ RTIC patología ocular del envejecimiento, calidad visual calidad de vida (OFTARED) Instituto de Salud Carlos III, Madrid, Spain

${ }^{7}$ Unidad de Gestión Clínica de Oftalmología. Hospitales Universitarios Virgen Macarena y Virgen del Rocío, Sevilla, Spain

${ }^{8}$ Unidad de Apoyo a la Investigación. Gerencia de Atención Primaria, Servicio Madrileño de Salud, Madrid, Spain

9Servicio de Evaluación de la Dirección del Servicio Canario Spain

Correspondence:

Dr MM Trujillo-Martín, Servicio

de Evaluación de la Dírección del

Servicio Canario de la Salud

(SESCS), Camino Candelaria, 44

C.S. San Isidro-El Chorrillo,

El Rosario, Tenerife 38109,

Spain

Tel: +34 922684019

Fax: +34 922680030

E-mail: mar.trujillomartin@sescs.es

Received: 17 June 2016 Accepted in revised form:

13 November 2016

Published online:

9 December 2016 University of Valladolid, de la Salud (SESCS), Tenerife, 
Spanish Ministry of Health, Social Services and Equality to the Evaluation Service of the Canary Islands Health Service (SESCS) as part of the Spanish Network of Agencies for Health Technology Assessment in the National Health System.

\section{Method of literature search}

\section{Information sources and search strategy}

The following electronic databases were searched (November 2016): Medline and PreMedline (OVID interface), EMBASE (Elsevier interface), SCI-EXPANDED (Web of Science interface), SSCI (Web of Science interface), and the Cochrane Library limited to trials (Wiley interface). Searches were limited to English and Spanish languages and human studies. No date restriction was imposed. The search strategy was developed initially in MEDLINE (Table 1) using controlled vocabulary and free text terms and then it was adapted for each of the other databases. Full search strategy is available from the study authors. Furthermore, to complete the systematic search, reference lists from retrieved articles were examined for additional citations.

\section{Selection criteria}

We included studies that assessed the effectiveness or safety of nutritional supplements for children or adults diagnosed with HRD. If a study addressed a heterogeneous group of patients, the study was included if the results for patients meeting our inclusion/exclusion criteria were reported separately or if they represented more than $80 \%$ of the target population. We included randomized controlled trials (RCTs), non-randomized controlled trials (nRCTs) and controlled observational studies. Comparison groups could be given standard of care, placebo, no treatment, or alternative treatments. We excluded publications with fewer than five study participants. Cross-sectional studies, qualitative research designs, reviews, meeting abstracts and protocols were also excluded. Outcome measures considered were clinical related with the visual function (eg, visual acuity, visual field and electroretinography parameters) and safety of interventions and/or patient-reported outcomes (eg, visual function, health-related quality of life). We excluded studies reporting only laboratory test results.

\section{Screening process}

Two reviewers evaluated titles and abstracts of the references identified by means of the search strategy independently and in parallel in order to reduce the possibility of rejecting relevant articles. The full text of those studies that appeared to fulfil pre-specified selection criteria was read and evaluated for inclusion. Differences

Table 1 Medline/PreMedline Search strategy

1. *Retinal Dystrophies/

2. *Retinitis Pigmentosa/

3. (Pigmentary retinopathy or Rod-cone dystroph* or Rod cone dystroph* or Retinal Dystroph* or Retinitis pigmentosa or pigmentary retinosis or retinosis pigmentary or retinosis pigmentosa or North Carolina Macular Distrophy or Stargardt-Fundus flavimaculatus or stargardt's fundus flavimaculatus or Stargardt's disease or Stargardt Macular Degeneration or Stargardt disease or fundus flavimaculatus or Sorsby dystrophy or Gyrate Atrophy or Atrophia Gyrata or Enhanced S-cone Syndrome or Goldman-Favre or Wagner-Stickler or vitreoretinal dystroph* or X-linked Juvenile retinoschisis or Occult Macular Dystrophy or Macular dystroph* or Choroideremia or Congenital Stationary Night Blindness or central areolar choroidal dystrophy or Bestrophinopathy or Bestrophinopathies or Best Vitelliform Macular Dystrophy or Vitelliform Macular Dystrophy or Familial Exudative vitreoretinopathy or adult-onset foveomacular Dystrophy or Butterfly-shaped pattern dystrophy or Pattern dystrophies in Retinal Pigment Epithelium or Autosomal dominant Stargardt-like macular dystrophy or Stargardt Macular Degeneration or Stargardt disease or hereditary retinal dystroph* or inherited retinal dystroph*).ab,ti.

4. 1 or 2 or 3

5. *Drug Therapy/ or *Therapeutics/ or *Disease Management/ or *Vitamins/

6. (therap* or drug therapy or intervention or interventions or treatment or treatments or disease management or Vitamin or Supplementation).ab,ti.

7. (Therapeutic adj2 (aspects or interventions or procedure)).ab,ti.

8. 5 or 6 or 7

9. *Treatment Outcome/

10. (Effectiveness or Efficacy or Security or Adverse effect or Adverse effects or Adverse event or Adverse events or Adverse reaction or Adverse reactions or Side effect).ab,ti.

11. 9 or 10

12. 4 and 8 and 11

13. limit 12 to humans

14. limit 13 to (english or Spanish)

15. remove duplicates from 14 
between reviewers were resolved through discussion with the research team until consensus was reached.

\section{Data collection process and assessment of risk of bias (methodological quality)}

A data extraction form was developed by the reviewers, pilot-tested on two studies and refined accordingly. One reviewer extracted the following data from the included studies: study design; methodology; participants (selection criteria, demographics, and comorbidities); interventions (type, regimen, and duration of supplementation); and results. A second reviewer subsequently verified the extracted data. If any required information was missing or unclear in the published article, an effort was made to contact the authors.

Two reviewers independently assessed the quality of included studies using the criteria of the Scottish Intercollegiate Guidelines Network (SIGN), ${ }^{7}$ which is based on a number of key questions that focus on those aspects of the study design with demonstrated significant influence on the validity of the results and conclusions. These key questions vary between studies with different designs and a range of checklists are used to bring a degree of consistency to the assessment process. Any disagreements between reviewers were resolved through discussion with the research team and subsequently by consensus.

\section{Analysis and synthesis}

A narrative synthesis with tabulated results was performed. Because of the high heterogeneity in methodological quality, interventions, and outcome measures of the included studies, it was not feasible combining data by means of meta-analysis.

For the preparation of this manuscript, we have followed the PRISMA Statement to report systematic reviews. ${ }^{8}$

\section{Results}

The results of the search and selection process are shown in Figure 1. From a total of 655 references initially identified after eliminating duplicates, we selected 64 potentially relevant articles after title and abstract screening. Finally, 8 studies informed in 13 articles were included in the present review. ${ }^{9-21}$

\section{Characteristics of studies}

The main characteristics of the selected studies are summarised in Table 2. All are randomised controlled trials, with a parallel design, 9,10,13,14,16 a crossover design, ${ }^{11,19,18}$ or a factorial design. ${ }^{12}$ Except Lee et al which studied Best disease, ${ }^{18}$ all included studies are on RP. ${ }^{9-17,19-21}$ They assessed supplements based on vitamin A and vitamin $\mathrm{E},{ }^{12}$ docosahexaenoic acid (DHA), 9,10,14,16,18 and the carotenoids lutein, ${ }^{11,13}$ and $\beta$-carotene. ${ }^{19}$ We did not identify eligible studies about other HRDs.

The quality of studies is generally acceptable, as it can be seen in the quality assessment provided in Table 2. Some studies have a very small sample size, especially the one published by Lee et al, with eight participants, and therefore their findings present a limited global application. ${ }^{18}$ In the opposite end we find the RCT with factorial design conducted by Berson et al ${ }^{12}$ with 601 randomised participants. Other included studies might be at risk of bias as they present a high rate of dropouts $(>20 \%),{ }^{9,11}$ or as in the study conducted by Hoffman et al in 2014 do not inform clearly about patients and researchers blinding procedure. ${ }^{18}$ The study by Bahrami et al has an important limitation regarding the method used for data recording, as they were documented by participants on their own using their personal computers. ${ }^{11}$ All studies performed intention-to-treat analysis with the exception of Rotenstreich et al. ${ }^{19}$

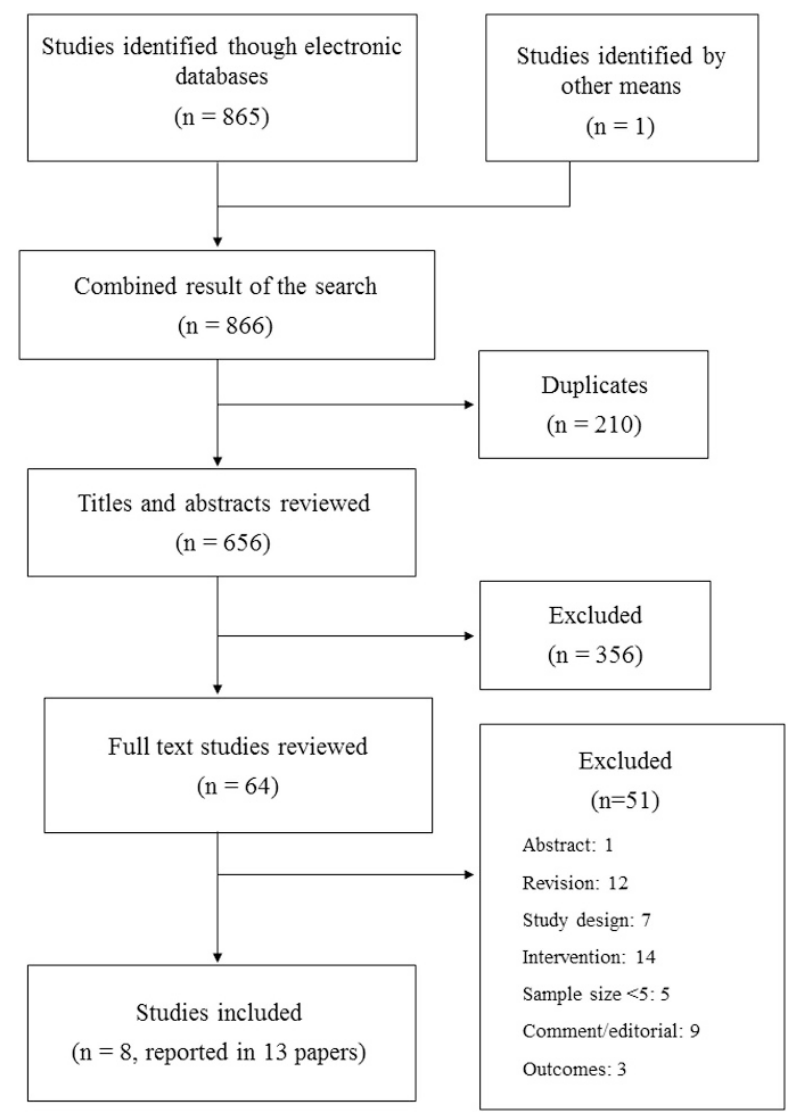

Figure 1 Flowchart for the selection of studies. 


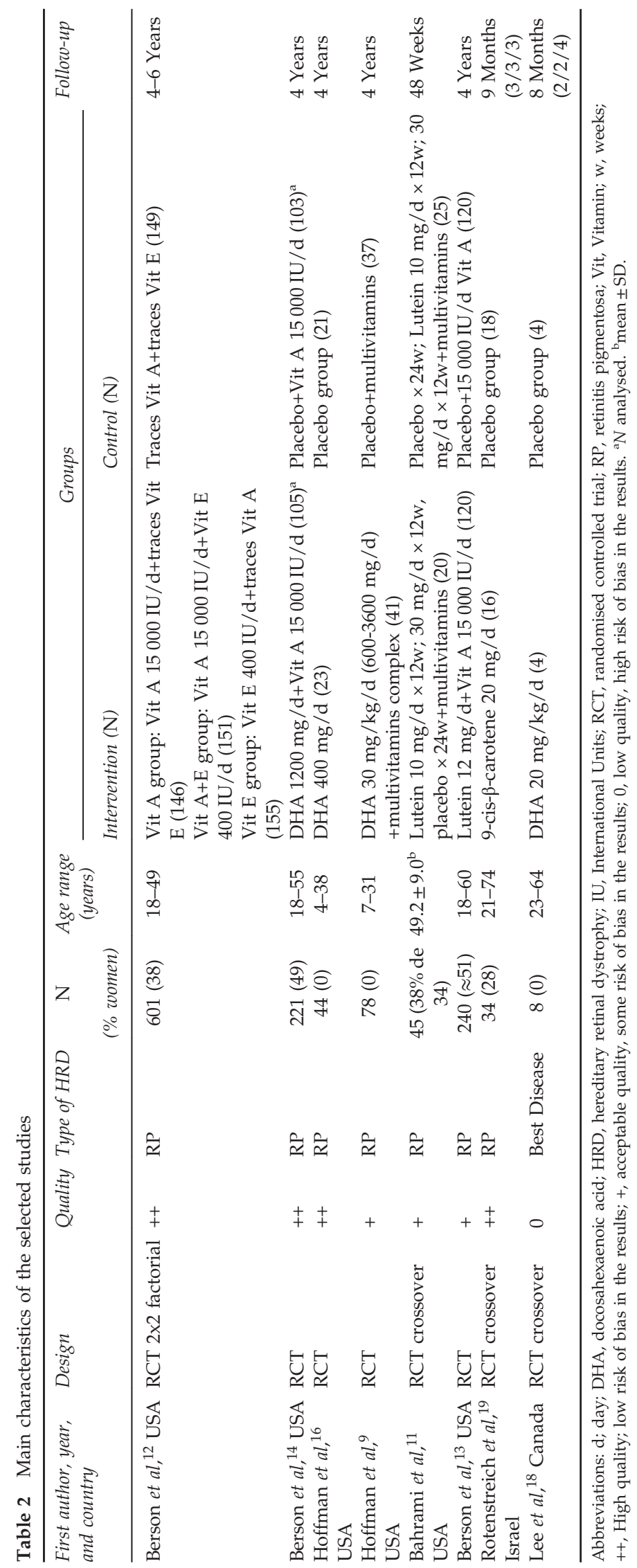




\section{Retinitis pigmentosa}

The selected studies assessed different supplementation strategies regarding composition, duration and dosage (Table 2). Berson et al assigned participants to four groups: vitamin $\mathrm{A}$, vitamin $\mathrm{E}$, vitamin $\mathrm{A}+\mathrm{E}$, and traces of both as control group. ${ }^{12}$ Some years after, Berson et al studied the additional effect of DHA supplementation in patients already receiving vitamin A. ${ }^{14}$ Hoffman et al evaluated the effect of DHA in males, as they only studied an X-linked RP which manifests mainly, but not exclusively, in men. ${ }^{16}$ In a subsequent trial by the same group, DHA dose was adapted to each participant's weight and a multivitamins supplementation providing $100 \%$ of recommended daily amounts of vitamins A, C, D, E, B6, and B12 was added to both groups. ${ }^{9}$ Bahrami et al ${ }^{11}$ and Berson et $a l^{13}$ studied supplementation with lutein in patients with different follow-up periods of 48 weeks and 4 years, respectively. Participants in Berson et al received also vitamin A regardless of the group they were assigned to. ${ }^{13}$ Finally, another carotenoid, 9 -cis- $\beta$-carotene from Dunaliella alga, was supplemented for 3 months on a crossover basis in the study by Rotenstreich et al, allowing a 3-month washout period between treatments. ${ }^{19}$

\section{Visual acuity}

Table 3 summarises the results for visual acuity. Berson et al reported a decline of visual acuity per year in all groups, with the larger decline in the group supplemented with both Vitamin A and E; however, the authors reported no significant differences among the four study arms ( $P$-values were not reported). ${ }^{12} \mathrm{~A}$ few years later, Berson et al ${ }^{14}$ did not find significant differences in visual acuity decline measured as ETDRS letters lost per year between the group receiving vitamin A plus DHA and the group receiving only vitamin A. In addition, both trials of Hoffman et al did not find any significant mean difference in visual acuity between DHA and placebo groups during a 4 years follow-up period. $9,10,16$

Regarding studies on lutein supplementation, Berson et al did not find additional effect of this carotenoid in the annual decline of ETDRS letters in a population supplemented with vitamin A. ${ }^{13}$ Bahrami et al found a statistically significant improvement $(P=0.018)$ of visual acuity related to lutein when measured in very low illumination conditions $(0.1 \%)$, but not in normal $(100 \%)$ or low $(4 \%)$ illumination conditions. ${ }^{11}$

In the study by Rotenstreich et $a l^{19}$ the ETDRS visual acuity improved slightly both in the $\beta$-carotene and placebo groups but without reaching statistical significance. No significant differences were observed either in the comparison between the groups.

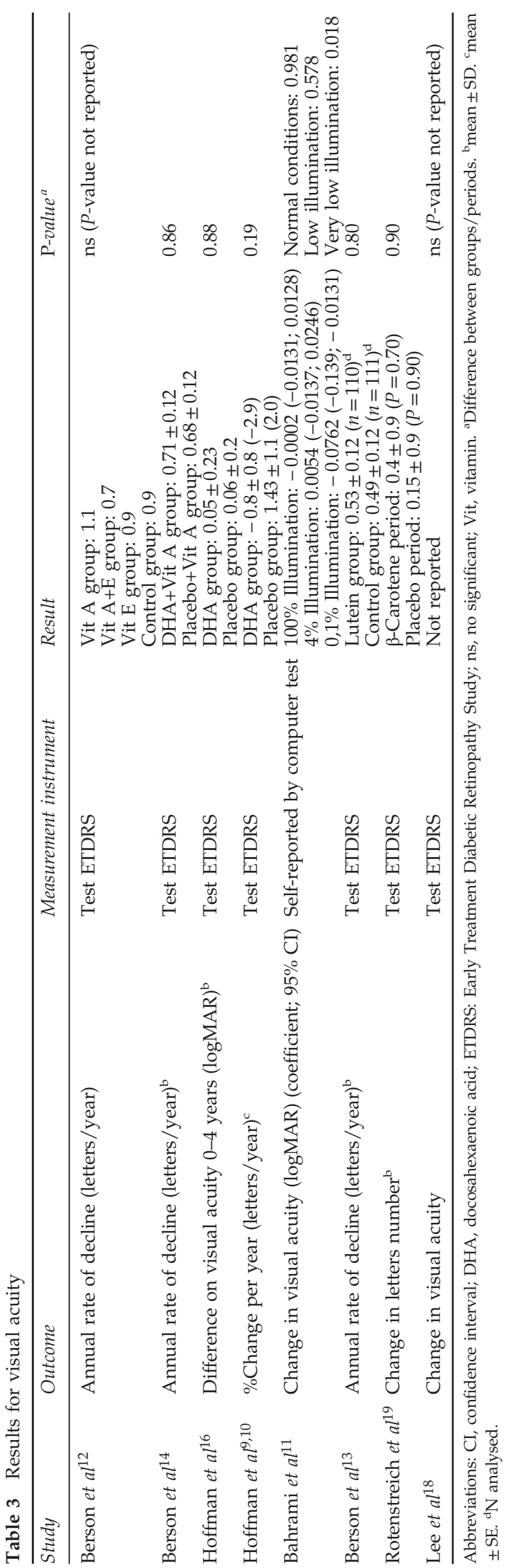




\section{Visual field}

Table 4 summarises the results for visual field. We found appreciable heterogeneity regarding the measurement of this outcome measure among studies. The annual rate of decline, change in perimetric visual field, change in visual field sensitivity, and rate of decline of visual field area, among others, were used.

Berson et al did not find a significant effect of vitamin A, vitamin $\mathrm{E}$ or both in the percentage of annual decline of the remaining visual field area. ${ }^{12}$ Berson et al in 2004 did not find any difference in the additional effect of DHA to vitamin $\mathrm{A}$ in the mean annual rates of decline of visual field sensitivity in any of the Humphrey field analyser programs they used. ${ }^{14}$ However, in a subsequent subgroup analysis which included only patients who were not receiving vitamin A before the trial onset $(n=208)$, they found significant differences in the decline of central and total visual field sensitivity for the group that received DHA plus vitamin A $(P=0.01)$, although the difference only occurred in the first 2 years of this 4-year study..$^{15}$ Finally, Hoffman et al ${ }^{16}$ found no statistically significant differences between groups in the mean visual field defect after four years (DHA group $2.4 \pm 3.66 \mathrm{~dB}$, versus placebo group $1.4 \pm 1.32 \mathrm{~dB}$, $P=0.29) .{ }^{16}$ However, a recent ancillary analysis ${ }^{10}$ of Hoffman ${ }^{9}$ shows that supplementation of DHA significantly slowed visual field sensitivity loss as compared with placebo $(\mathrm{P}<0.0001)$.

In the trial of Berson et al, ${ }^{13}$ a statistically significant positive effect of lutein in the annual rate of decline of the mid-peripheral visual field was found in a non-smoking adult population $(P=0.05)$. This effect was not found either for central visual field or for the annual rate of decline in combined central and mid-peripheral visual field sensitivity. In another paper studying lutein, ${ }^{11}$ the rate of decline of central visual field was positively affected by lutein for the pre-post comparison $(P<0.001)$ and similarly, changes in visual field area improved when comparing supplementation and placebo periods $(P=0.038$; or $P=0.001$ if using a model with 6 weeks delay of the lutein effect).

Rotenstreich et al found a significant improvement of the visual field area in dark-adapted conditions during a 9-cis $\beta$-carotene supplementation period, something that did not occur during the placebo period. However, the difference between treatments was not statistically significant. In light-adapted conditions, this parameter improved during $\beta$-carotene periods but without reaching statistical significance. The difference was not significant during the placebo period or when comparing periods. The authors opined that the unexpected improvement in visual field area during the placebo treatment might be related to an insufficient washout. It is also possible it is part of the usual fluctuations in RP patients. ${ }^{19}$

\section{Electrorretinogram (ERG) amplitude response}

Table 5 summarises the results for ERG. Berson et al in 1993 reported a relative protective effect of vitamin A in the annual rate of decline in ERG amplitude compared with vitamin $\mathrm{E}$ and placebo $(P=0.01)$. This difference was even higher in a subgroup analysis of the cohort with the highest ERG amplitude at baseline $(P=0.001)$. In addition, the groups receiving vitamin E experienced a more pronounced decline than those not receiving it $(P=0.04)$. In line with the previous findings, result for the percentage of patients surviving with less than $50 \%$ decline in $30 \mathrm{~Hz}$ ERG amplitude from baseline was also positive for the vitamin A group $(P=0.01)$, moreover, those not receiving vitamin $\mathrm{E}$ maintained their initial ERG amplitude better than those receiving it $(P=0.03) .{ }^{12}$

Berson et $\mathrm{l}^{14}$ found no significant differences in the annual rate of decline of $30 \mathrm{~Hz}$ cone ERG amplitude between vitamin A supplemented patients and vitamin A plus DHA supplemented patients in a 4 years followup period. ${ }^{14}$

The study by Hoffman et al reported a nonsignificant difference in change in cone ERG amplitude between DHA and placebo groups even though the decline was less severe in the DHA group. These results could be limited by the study design, as sample size estimation was derived from a predicted decrease of $0.085 \log$ units/ year, and the actual decrease observed was 0.066. In a subgroup analysis they found a significant effect of DHA in rod ERG amplitude for prepubescent patients younger than 12 years $(P=0.04)$; in contrast, postpubescent patients 12 years and older had a significant reduction in the rate of cone ERG functional loss $(P=0.038)$, but not in rods. ${ }^{16}$ Subsequently, in a further study, Hoffman $e t a l^{9}$ found no effect of DHA treatment in the rate of cone ERG functional loss, even though the functional loss in both treatment group and control group was markedly slower than in a previous study, ${ }^{16}$ especially in the placebo group. No significant differences between groups in the rate of maximal ERG functional loss and in the rate of rod ERG functional loss were reported. ${ }^{9}$

In the study conducted by Berson et al, ${ }^{13}$ it was not possible to observe a significant effect of lutein in the annual rate of decline of ERG amplitude when compared with placebo.

In Rotenstreich et al ${ }^{19}$ mean change in scotopic maximal amplitude of cones-rods improved by $39.8 \%$ $(P=0.002)$ during the $\beta$-carotene supplementation period and decreased by $15.9 \%(P=0.20)$ during placebo treatment period (comparison between treatments 
Table 4 Results for visual field

\begin{tabular}{|c|c|c|c|c|}
\hline Study & Outcome & Measurement instrument & Result & P-value $e^{\mathrm{a}}$ \\
\hline \multirow[t]{4}{*}{ Berson et $a l^{12}$} & $\begin{array}{l}\text { Percentage of decline } \\
\text { of remaining } \\
\text { visual field area }\end{array}$ & $\begin{array}{l}\text { Goldmann perimetry } \\
\text { (V-4-e white light) }\end{array}$ & Vit A group: 5.6 & ns ( $P$-value not reported) \\
\hline & & & Vit A+E group: 6.2 & \\
\hline & & & Vit E group: 6.3 & \\
\hline & & & Control group: 5.9 & \\
\hline \multirow[t]{4}{*}{ Berson et al ${ }^{14}$} & $\begin{array}{l}\text { Annual rate of decline } \\
\text { of visual field } \\
\text { sensitivity }(\mathrm{dB} / \text { year })^{\mathrm{b}}\end{array}$ & $\begin{array}{l}\text { Humphrey HFA, } \\
\text { program 30-2 }\end{array}$ & DHA+Vit A group: $36.95 \pm 3.36$ & 0.88 \\
\hline & & & Placebo+Vit A group: $37.68 \pm 3.36$ & \\
\hline & & $\begin{array}{l}\text { Humphrey HFA, } \\
\text { programs } 30-2 \text { and } \\
30 / 60-1 \text { combined }\end{array}$ & DHA+Vit A group: $57.21 \pm 4.90$ & 0.73 \\
\hline & & & Placebo+Vit A group: $59.59 \pm 4.90$ & \\
\hline \multirow[t]{2}{*}{ Hoffman et al ${ }^{16}$} & $\begin{array}{l}\text { Difference in mean } \\
\text { visual field defect }(\mathrm{dB})^{\mathrm{b}}\end{array}$ & $\begin{array}{l}\text { Humphrey HFA 640, } \\
\text { program } 30-2\end{array}$ & DHA group: $2.4 \pm 3.66(0.24 \mathrm{log})$ & 0.29 \\
\hline & & & Placebo group: $1.4 \pm 1.32(0.14 \mathrm{log})$ & \\
\hline \multirow[t]{2}{*}{ Hoffman et $a l^{9,10}$} & $\begin{array}{l}\text { Percentage of annual } \\
\text { rate of progression for } \\
\text { the overall reduction } \\
\text { of loss }\end{array}$ & $\begin{array}{l}\text { Humphrey HFA 640, } \\
30-2 \text { and } 30 / 60-2\end{array}$ & DHA group: $-0.39 \pm 0.02(-4.5)$ & $<0.0001$ \\
\hline & & & Placebo group: $-0.86 \pm 0.02(-6.9)$ & \\
\hline \multirow[t]{5}{*}{ Berson et al ${ }^{13}$} & $\begin{array}{l}\text { Rate of decline in } \\
\text { central visual field } \\
\left(^{\left(\mathrm{dB} / \text { year }^{\mathrm{b}}\right.}\right.\end{array}$ & $\begin{array}{l}\text { Humphrey HFA II, } \\
\text { program } 30-2\end{array}$ & Lutein group: $49.6 \pm 3.3(n=105)^{\mathrm{d}}$ & 0.66 \\
\hline & & & Control group: $51.5 \pm 3.2(n=110)^{\mathrm{d}}$ & \\
\hline & $\begin{array}{l}\text { Rate of decline in } \\
\text { mid-peripheral visual } \\
\text { field sensitivity } \\
\text { (dB/year) }^{\mathrm{b}}\end{array}$ & $\begin{array}{l}\text { Humphrey HFA II, } \\
\text { program } 60-4\end{array}$ & Lutein group: $26.6 \pm 3.1(n=81)^{\mathrm{d}}$ & 0.05 \\
\hline & & & Control group: $34.1 \pm 3.0(n=82)^{\mathrm{d}}$ & \\
\hline & $\begin{array}{l}\text { Rate of decline in total } \\
\text { field sensitivity } \\
\text { (dB/year) }^{\mathrm{b}}\end{array}$ & $\begin{array}{l}\text { Programs } 30-2 \text { and } 60-4 \\
\text { combined }\end{array}$ & Lutein group: $83.1 \pm 6.2(n=79)^{\mathrm{d}}$ & 0.24 \\
\hline \multirow{3}{*}{ Bahrami et al ${ }^{11}$} & & & Control group: $92.9 \pm 5.7(n=78)^{\mathrm{d}}$ & \\
\hline & $\begin{array}{l}\text { Percentage of visual } \\
\text { field (change per } \\
\text { week) }(95 \% \mathrm{CI})\end{array}$ & $\begin{array}{l}\text { Self-reported by } \\
\text { personal computer }\end{array}$ & $-0.2 \%(-0.003 ;-0.001)$ & $<0.001^{\mathrm{f}}$ \\
\hline & $\begin{array}{l}\text { Change in visual field } \\
\text { area }^{\mathrm{e}}(95 \% \mathrm{CI})\end{array}$ & $\begin{array}{l}\text { Self-reported by } \\
\text { personal computer }\end{array}$ & 0.018 higher $(0.001 ; 0.0355)$ & 0.038 \\
\hline \multirow[t]{4}{*}{ Rotenstreich et al ${ }^{19}$} & $\begin{array}{l}\text { Change in visual field } \\
\text { area in dark-adapted } \\
\text { conditions }\left(\mathrm{cm}^{2}\right)^{\mathrm{b}}\end{array}$ & Goldmann perimetry & $\beta$-Carotene period: $8.6 \pm 3.8(P=0.03)$ & 0.40 \\
\hline & & & Placebo period: $3.8 \pm 3.8(P=0.30)$ & \\
\hline & $\begin{array}{l}\text { Change in visual field } \\
\text { area in light-adapted } \\
\text { conditions }\left(\mathrm{cm}^{2}\right)^{\mathrm{b}}\end{array}$ & Goldmann perimetry & $\beta$-Carotene period: $7.8 \pm 4.5(P=0.09)$ & 0.19 \\
\hline & & & Placebo period: $-0.5 \pm 4.5(P=0.90)$ & \\
\hline \multirow[t]{2}{*}{ Lee $e t a l^{18}$} & $\begin{array}{l}\text { Visual field mean } \\
\text { deviation }\end{array}$ & $\begin{array}{l}\text { Humphrey HFA II, } \\
\text { program } 10-2\end{array}$ & Not reported & ns ( $P$-value not reported) \\
\hline & $\begin{array}{l}\text { Visual field pattern } \\
\text { deviation }\end{array}$ & $\begin{array}{l}\text { Humphrey HFA II, } \\
\text { program } 10-2\end{array}$ & Not reported & $\begin{array}{l}\text { first and combined } \\
\text { crossovers had statistically } \\
\text { significant } P \text {-values of } \\
0.036 \text { and } 0.011 \\
\text { respectively, with } \\
\text { significance for the } \\
\text { crossover to the } \\
\text { placebo period }\end{array}$ \\
\hline
\end{tabular}


Table 5 Results for ERG

\begin{tabular}{|c|c|c|c|}
\hline Study & Outcome & Result & P-value $e^{\mathrm{a}}$ \\
\hline \multirow[t]{5}{*}{ Berson $e$ a $\mathrm{l}^{12}$} & Percentage of decline in $30 \mathrm{~Hz}$ ERG amplitude & $\begin{array}{l}\text { Vit A group: } 6.1(8.3)^{\mathrm{b}} \\
\text { Vit A+E group: } 6.3(8.8)^{\mathrm{b}}\end{array}$ & Vit A group: $0.01(0.001)^{c}$ \\
\hline & & $\begin{array}{l}\text { Vit E group: } 7.9(11.8)^{\mathrm{b}} \\
\text { Control group: } 7.1(10)^{\mathrm{b}}\end{array}$ & Vit E group: $0.45(0.04)^{\mathrm{c}}$ \\
\hline & $\begin{array}{l}\text { Percentage of patients surviving with less than } \\
50 \% \text { decline } \\
\text { in } 30 \mathrm{~Hz} \text { ERG amplitude in year } 6 \text { from baseline }\end{array}$ & Vit A group: 62 & Vit A group: 0.01 \\
\hline & & Vit A+E group: 50 & \\
\hline & & $\begin{array}{l}\text { Vit E group: } 27 \\
\text { Control group: } 48\end{array}$ & Vit E group: 0.03 \\
\hline Berson et al ${ }^{14}$ & Annual rate of decline of $30 \mathrm{~Hz}$ cone ERG amplitude $\log ^{\mathrm{e}}$ & $\begin{array}{l}\text { DHA+Vit A group: } \\
0.10 \pm 0.01(9.92) \\
\text { Placebo+Vit A group: } \\
0.11 \pm 0.01(10.49)\end{array}$ & 0.64 \\
\hline Hoffman et al ${ }^{16}$ & Change in cone ERG amplitude in 4 years $(\log \mu \mathrm{V})^{\mathrm{c}}$ & $\begin{array}{l}\text { DHA group: }-0.199 \pm 0.172 \\
\text { Placebo group: } \\
-0.266 \pm 0.173\end{array}$ & 0.20 \\
\hline \multirow[t]{3}{*}{ Hoffman et $a l^{9}$} & $\begin{array}{l}\text { Rate of cone ERG amplitude functional loss (log } \mu \mathrm{V}(\mathrm{SD}) \text {; } \\
\text { mean } \mu \mathrm{V}(\mathrm{SD}) ; \% \text { annual decline) }\end{array}$ & $\begin{array}{l}\text { DHA group: }-0.028(0.001) \\
-0.94 \text { (1.00); } 6.2 \\
\text { Placebo group: }-0.022 \\
(0.002) ;-0.95(1.00) ; 4.3\end{array}$ & 0.30 \\
\hline & $\begin{array}{l}\text { Rate of rod ERG amplitude functional loss (log } \mu \mathrm{V}(\mathrm{SD}) \text {; } \\
\text { mean } \mu \mathrm{V} \text { (SD); \% annual decline) }\end{array}$ & $\begin{array}{l}\text { DHA group: }-0.010(0.001) \\
-0.98(1.00) ; 2.3 \\
\text { Placebo group: }-0.023 \\
(0.001) ;-0.95(1.00) ; 6.0\end{array}$ & 0.27 \\
\hline & $\begin{array}{l}\text { Rate of maximal ERG amplitude functional loss } \\
\text { (log } \mu \mathrm{V}(\mathrm{SD}) ; \text { mean } \mu \mathrm{V} \text { (SD); \% annual decline) }\end{array}$ & $\begin{array}{l}\text { DHA group: }-0.042(0.001) \\
-0.91 \text { (1.00); } 9.2 \\
\text { Placebo group: }-0.036 \\
(0.001) ;-0.92(1.00) ; 8.0\end{array}$ & 0.65 \\
\hline Berson et al ${ }^{13}$ & $\begin{array}{l}\text { Annual rate of decline of } 30 \mathrm{~Hz} \text { ERG amplitude } \\
\left(\log _{\mathrm{e}} \% \text {; } \text {; mean result) }\right.\end{array}$ & $\begin{array}{l}\text { Lutein group: } 0.09 \pm 0.01 ; 8.4 \\
(\mathrm{n}=79)^{\mathrm{d}} \\
\text { Control group: } 0.08 \pm 0.12 \\
7.7(\mathrm{n}=77)^{\mathrm{d}}\end{array}$ & 0.59 \\
\hline \multirow[t]{3}{*}{ Rotenstreich et al ${ }^{19}$} & Change in scotopic maximal cones-rods function $(\mu \mathrm{V})^{c}$ & $\begin{array}{l}\beta \text {-Carotene period: } 8.4 \pm 2.8 \\
(P=0.004) \\
\text { Placebo period: }-5.9 \pm 2.8 \\
(P=0.04)\end{array}$ & 0.001 \\
\hline & Change in light-adapted cone function $(\mu \mathrm{V})^{c}$ & $\begin{array}{l}\beta \text {-Carotene period: } 3.4 \pm 1.5 \\
(P=0.03)\end{array}$ & Absolute values: 0.06 \\
\hline & & $\begin{array}{l}\text { Placebo period: }-0.7 \pm 1.5 \\
(P=0.60)\end{array}$ & $\%$ of change: $0.01^{\mathrm{e}}$ \\
\hline Lee et $a l^{18}$ & $\begin{array}{l}\text { Multifocal ERG central y-peripheral, EOG Arden index, } \\
\text { in each eye }\end{array}$ & Not reported & ns ( $P$-value not reported) \\
\hline
\end{tabular}

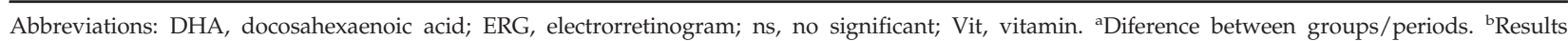
referred to the cohort with the highest ERG amplitude at baseline $(n=354) .{ }^{c}$ mean \pm SD. ${ }^{\mathrm{d}} N$ analysed. Percentages available in the text.

$P=0.002)$. Similarly, mean change values in lightadapted cone ERG function improved by $17.8 \%$ $(P=0.003)$ during the supplementation period and declined by $3 \%(P=0.60)$ during the placebo period (comparison between treatments $P=0.001$ ). See Table 5 for absolute values.

\section{Patient self-perceived visual function}

Table 6 summarises the results for patient self-perceived visual function. Only Hoffman et al used this outcome to assess the effect of supplementation (DHA) in RP. The authors measured annual mean scores for the eight attributes of the visual activities questionnaire (VAQ). The difference between groups was not statistically significant for any attribute. ${ }^{16}$

\section{Adverse effects}

Berson et al assessed safety of vitamin A and vitamin E supplementation by symptom questionnaires, serum measurements of liver function and questions during 


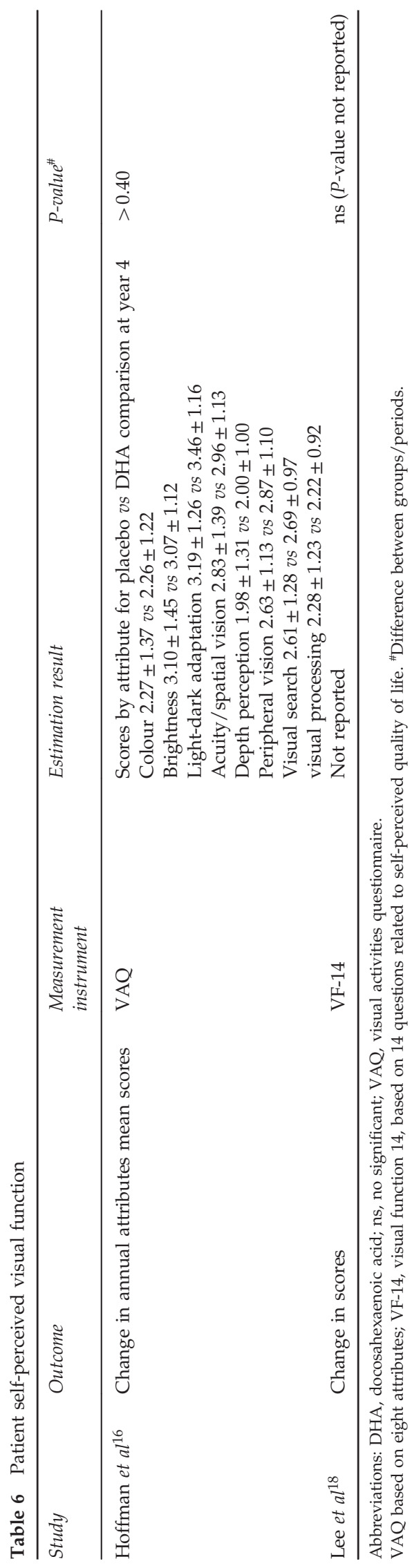

follow-up visits. They reported no adverse effects. ${ }^{12}$ A subsequent article reporting long-term safety on the same sample added in the calculation of dietary vitamin A intake to the supplemented dosage, concluded that there was no difference regarding adverse effects between participants consuming $18609 \mathrm{IU} /$ day of vitamin A on average and those consuming a much lower vitamin A dosage (3511 IU/day on average). This result at 5 years was also maintained in a 12 years follow-up subsample. ${ }^{20}$

The trial by Berson et al on Vitamin A and DHA did not report any adverse effects in the 4 years follow-up period. ${ }^{14}$ Similarly, Hoffman et al did not observe severe adverse events, ${ }^{16}$ nevertheless an additional publication of this study focusing on biological safety and adverse events reported the occurrence of minor adverse events equally distributed between the DHA and control groups. Some of these events were consistent with normal events of adolescence (acne, headaches or weight gain) while others were related to the consumption of DHA capsules (nausea, flatulence and eructation, among others). ${ }^{21}$

Through quarterly diaries and in the annual follow-up visits, Hoffman et al gathered self-reported treatmentemergent adverse events. No severe adverse effects were reported. They reported 22 and 20 minor events in the DHA and control group, respectively. A case of gastrointestinal problems in a DHA sensitive patient with family history of Crohn's disease was also reported. ${ }^{9}$ A complementary publication reported in detail serum values and adverse events related to treatment data of those participants completing $\geq 1$ year. ${ }^{17}$

Berson et al reported no evidence of toxicity or systemic illness attributable to vitamin A or lutein. This was based on blood studies, serum liver function assessments, serum retinol and serum retinyl ester values, and responses to a symptoms questionnaire over the follow-up period of the trial (4 years). ${ }^{13}$ In the study by Baharami et al one participant on lutein and two on placebo group showed impaired liver function tests, but levels returned to normal when tests were repeated. ${ }^{11}$

Finally, Rotenstreich et al found no relevant adverse effects of 9 -cis $\beta$-carotene during the trial period or in the following 3 years after the trial end that the supplementation was continued. ${ }^{19}$

\section{Best vitelliform macular dystrophy}

Lee et al randomly assigned members of three families $(\mathrm{n}=8)$ to receive $20 \mathrm{mg} / \mathrm{kg} /$ day of DHA or placebo for 2 months. Then treatment was switched between groups for 2 months and switched back for an additional period of 4 months, with no washout periods in between. ${ }^{18}$ Results of this study are shown in Tables 3-6. 


\section{Visual acuity}

No significant differences were found during the supplementation and placebo periods or in the comparison between them.

\section{Visual field}

No significant differences were found during the supplementation and placebo periods neither in the comparison between them. However, the first crossover and the combined analysis of crossovers had statistically significant $P$-values of 0.036 and 0.011 , respectively, with significance for the crossover to the placebo period.

\section{ERG amplitude response}

Comparison of the variations in the combined crossovers showed that the central and peripheral multifocal ERG and electro-oculogram were all not statistically significant.

\section{Patient self-perceived visual function}

No significant differences were found in any comparison for the VF-14 visual function index.

\section{Adverse effects}

The study did not report adverse events of any severity or characteristic.

\section{Other HRD studies not included in this review}

We identified studies for other HRDs that did not meet the pre-determined selection criteria, however, given the scarcity of available evidence, we think it is interesting to briefly comment on them. The effect of vitamin $\mathrm{A}$ and $\mathrm{E}$ in abetalipoproteinaemia and hypobetalipoproteinaemia, ${ }^{22}$ the effect of lutein in Stargardt disease, ${ }^{23}$ the effect of creatine, ${ }^{24}$ and lysine in gyrate atrophy, ${ }^{25}$ and the effect of 9 -cis $\beta$-carotene in fundus albipunctatus ${ }^{26}$ has been tested. Methodological quality of these studies was assessed as very low for different reasons such as study design or too small sample size, among other considerations.

\section{Discussion}

The present systematic review confirms the scarcity of evidence on nutritional supplementation effectiveness for HRDs group of diseases, with the exception of RP.

Included studies, but the small clinical trial by Lee et al on DHA and the Best disease, ${ }^{18}$ investigate the effect on RP of vitamin supplements, DHA fatty acid, or carotenoids. ${ }^{9,11-14,16,19}$ There are hypothetical potential explanations that may explain this situation, as the presence of high levels of DHA in the outer segment of cones and rods membranes, possibly providing both a protective and cell proliferation function. ${ }^{27,28}$ Moreover, antioxidants like vitamin A, E and carotenoids might have a protective effect against photoreceptor cells membrane degeneration. ${ }^{29}$

Although in an analysis of the selected studies might suggest a protective effect of vitamin A on ERG when assessed by $30 \mathrm{~Hz}$ amplitude decline, ${ }^{12}$ this effect did not show on other ERG parameters or other outcomes such as visual acuity and visual field measurements. Vitamin E, conversely, was concluded to have had a detrimental effect in visual function as shown by a significantly higher annual rate of decline of ERG amplitude in the supplementation group compared with the placebo group. DHA does not seem to produce an additional effect on individuals who are already supplemented with vitamin A. ${ }^{14}$ It must be remarked that the dose of $15000 \mathrm{IU} /$ day for 4 years was said to not cause adverse effects in these two studies, especially on the hepatic function, as vitamin A is accumulated in the liver and secreted later as retinol to the bloodstream. Two important remarks must be made regarding these studies. Firstly, Berson et al reported in their study from $1993^{3}$ that a significant protective effect on ERG amplitude decline between vitamin A groups and those groups without vitamin A occurred at years 1, 2, 5 and 6, but not at years 3 and 4 . The study was planned to last 4 years but, according to authors, it finally lasted longer due to recruitment rate problems. Secondly, as it was discussed by Massof and Finkelstein ${ }^{30}$ and Massof and Fishman ${ }^{31}$ regarding Berson's 1993 and 2004 studies, respectively, 3,5 we must be cautious about the risk of misinterpreting outcomes because of assumptions built into the data analysis, and on the weight we place on clinical practice recommendations that are based on secondary analyses, especially in outcome measures not directly related to the loss of visual function (as ERG). This controversy between Berson and Massof, started in 1993 and continued in 2010, must be taken into account when reading the positive conclusions of the aforementioned studies.

The two studies by Hoffman et al suggest that DHA has no clear effect in the progression of X-linked RP.9,16 The rather low dosage used by the authors in the first study (400 mg/day) was corrected in the second to fit the individual age and weight characteristics of participants (ranging 600-3600 mg/day). The promising results of the secondary analysis in Hoffman et al ${ }^{16}$ for the ERG of rods (patients younger than 12 years old) and cones (patients 12 years old and older) were not confirmed later in their study of $2014 .{ }^{9}$ This study failed to show positive results for visual acuity but informed a trend to a reduced annual 
rate in the progression of loss of visual field sensitivity. However, in our opinion, this isolated mild positive result for DHA, especially when found in an ancillary analysis, ${ }^{10}$ does not constitute a solid evidence of effectiveness for this supplement. Regarding safety evidence, the authors commented on the need for a cautious approach when applying fatty acid supplementation to patients with a family history of gastrointestinal intolerance (as in Crohn's disease).

The evidence from the studies included in this review suggested a positive but limited antioxidant protective effect of carotenoids on the progression of RP. ${ }^{11,13}$ The results for lutein showed a reduced rate of decline in midperipheral visual field sensitivity but not in other parameters related to visual field or visual acuity for lutein. Again, the positive effect of lutein was shown in a secondary outcome measure but not in the primary one, generating the same already mentioned concerns raised in previous studies. ${ }^{31}$ Lutein can be found in the outer segments of the photoreceptors in the retina, and might possibly act as an antioxidant agent against high-energy short-wavelength illumination. ${ }^{13}$ This effect was observed in patients also receiving $15000 \mathrm{IU} /$ day of vitamin A. The mild but statistically significant beneficial effect of lutein on visual acuity in $0.1 \%$ illumination conditions, as well as on visual field, must be interpreted with caution due to the conditions of measurement for outcomes data record, in Bahrami et al, ${ }^{11}$ as data were self-recorded by participants using their home or work personal computers. Results for lab variables were published only as a conference presentation; however, we had access to these data through the authors and no significant positive results were obtained in the relevant variables. ${ }^{32}$

The other carotenoid, 9-cis B-carotene, was observed to have positive effect on visual function degeneration, on the visual area in dark conditions and especially on the ERG parameters (amplitude changes). ${ }^{19}$ This observation is in need of further confirmation by other investigators before a recommendation is justified on a large scale basis.

The fact that carotenoids did not cause severe adverse effects in the participants of the studies considered is quite promising for these compounds to be used as a potentially safe treatment for RP. However, there exist important concerns on this issue. The meta-analysis conducted by Druesne-Pecollo et al that found an increased risk of lung and stomach cancers in smokers and asbestos workers supplemented with doses higher than $20 \mathrm{mg}$ /day of $\beta$-carotene. ${ }^{33} \mathrm{New}$ studies should confirm the findings of Bahrami et al, ${ }^{11}$ Berson et al, ${ }^{13}$ and Rotenstreich et $a{ }^{1},{ }^{19}$ as well as determine the safest and most effective supplementation dosage, with special caution with regards to the potential toxicity in certain types of patients, as previously commented.
Lee et $a l^{18}$ did not find a positive effect of DHA in patients with Best vitelliform macular dystrophy. This could be explained by the low dosage regime (Hoffman et $a l^{16}$ used a higher dosage with no adverse effect), the small sample studied, or the advanced disease stage of the participants given the age ( 40.5 years old on average). The remaining effect of DHA could explain the positive results in the visual field measurements during the placebo period. Further studies with a higher dosage and a larger sample might better shed light on the effect of DHA in Best disease patients.

Finally, among the studies that could not be included in the review, it is interesting to note that one of them places $\beta$-carotene as a promising treatment for fundus albipunctatus, with an apparent lack of short-term toxicity of a high-dosage regime in a non-smoking population. ${ }^{26}$

To avoid selection bias when performing this systematic review, a set of inclusion and exclusion criteria were pre-established. An exhaustive search using multiple databases was followed by an independent evaluation of all retrieved papers by two reviewers. However, this systematic review is not free from limitations. First, only a limited number of studies evaluating supplementation interventions in HRD patients were identified. The review was limited to studies written in English and Spanish, and grey and unpublished literature was not considered, which is likely to impact the results of the review. Other limitations are the small sample size of the trials, the heterogeneity of outcome measures and the lack of long-term data, as it may be that some positive effects on the short and midterm could not affect the course of the disease in the longterm. Finally, as in any systematic review, the results and conclusions presented here are dependent on the inherent limitations of the included studies.

On the basis of published data, vitamin A and the carotenoids lutein and $\beta$-carotene may have a limited effect on RP progression; it could be that some welldesigned additional studies could achieve more robust conclusions, especially regarding combined supplements strategies. These conclusions on RP are consistent with the conclusions drawn by Sacchetti et al ${ }^{5}$ in a previous review, where a small effect of vitamin $A$ and $\beta$-carotene and no effect of DHA were reported. The aforementioned supplements can potentially be a safe treatment in the dosage regimes used in the studies included in this review. Still, it must be remarked however that it is necessary to take a cautious approach regarding the use of liposoluble vitamins, vitamin A particularly, as high doses may have a role for instance in the pathogenesis of idiopathic intracranial hypertension ${ }^{34,35}$ or cause liver toxicity in individuals with previous liver conditions or under chronic use of liver-metabolised medication. ${ }^{36}$ 
Moreover, studies in rodents suggest problems of vitamin A for individuals carrying a mutation at ABCD4. ${ }^{37}$ $\beta$-carotene in doses over $20 \mathrm{mg} /$ day, can increase the incidence of lung and stomach cancer in smoking and asbestos exposed patients. ${ }^{8}$ Because of both the ambiguity and uncertainty as to the true value of those nutritional supplements reviewed in the manuscript, the use of these supplements should be used with caution. The published data do not show a positive effect of DHA on RP or the Best disease, both when administered as an individual supplement or in combination with vitamin A. Moreover, the scarcity of evidence available on the treatment of HRDs other than RP with nutritional supplements, reveals a need for further research efforts.

\section{Conflict of interest}

The authors declare no conflict of interest.

\section{Acknowledgements}

This work was supported by the Institute of Health Carlos III, an autonomous organisation of the Spanish Ministry of Economy and Finance, in cooperation with the Evaluation Service of the Canary Islands Health Service (SESCS), in the framework of the activities developed by the Spanish Network of Agencies for Health Technology Assessment for the National Health Service financed by the Spanish Ministry of Health, Social Services and Equality. We thank the information specialist Mrs Leticia Cuellar Pompa for the development of the search strategies for electronic literature databases. We also thank Ms Rowan Maxwell for her assistance in improving the English language of the present manuscript.

\section{Search terms and databases}

Electronic searches were performed on Medline and PreMedline, EMBASE, SCI-EXPANDED, SSCI, and The Cochrane Library. The search strategy was developed initially in MEDLINE using controlled vocabulary and free text terms and then it was adapted for each of the other databases. Searches were limited to the English and Spanish languages and no date restriction was imposed. The Medline search strategy is presented in Table 1 and the full search strategy is available from the study authors.

\section{References}

1 Inglehearn C. Molecular genetics of human retinal dystrophies. Eye 1998; 12(Pt 3b): 571-579.

2 Givre S, Gard S. Retinitis pigmentosa: clinical presentation and diagnosis. UpToDate (2014). Available at: http://www. uptodate.com/contents/retinitis-pigmentosa-clinicalpresentation-and-diagnosis (accessed 19 June 2015).

3 Hodge WG, Barnes D, Schachter HM, Pan YI, Lowcock EC, Zhang $\mathrm{L}$ et al. The evidence for efficacy of omega-3 fatty acids in preventing or slowing the progression of retinitis pigmentosa: a systematic review. Can J Ophthalmol 2006; 41(4): 481-490.

4 Rayapudi S, Schwartz S, Wang X, Chavis P. Vitamin A and fish oils for retinitis pigmentosa. Cochrane Database Syst Rev 2013; (12): CD008428.

5 Sacchetti M, Mantelli F, Merlo D, Lambiase A. Systematic review of randomized clinical trials on safety and efficacy of pharmacological and nonpharmacological treatments for retinitis pigmentosa. J Ophthalmol 2015; 2015: 737053.

6 Weleber R, Kurz D, Trzupek K. Treatment of retinal and choroidal degenerations and dystrophies: current status and prospects for gene-based therapy. Ophthalmol Clin North Am 2003; 16(4): 583-593.

7 Scottish Intercollegiate Guidelines Network (SIGN). SIGN 50: A guideline Developer's Handbook. SIGN: Edinburgh, 2014.

8 Liberati A, Altman DG, Tetzlaff J, Mulrow C, Gøtzsche PC, Ioannidis JPA et al. The PRISMA statement for reporting systematic reviews and meta-analyses of studies that evaluate healthcare interventions: explanation and elaboration. BMJ 2009; 339: b2700.

9 Hoffman DR, Hughbanks-Wheaton DK, Pearson NS, Fish GE, Spencer R, Takacs A et al. Four-year placebocontrolled trial of docosahexaenoic acid in X-linked retinitis pigmentosa (DHAX trial): a randomized clinical trial. JAMA Ophthalmol 2014; 132(7): 866-873.

10 Hoffman DR, Hughbanks-Wheaton DK, Spencer R, Fish GE, Pearson NS, Wang YZ et al. Docosahexaenoic acid slows visual field progression in $\mathrm{X}$-linked retinitis pigmentosa: ancillary outcomes of the DHAX trial. Invest Ophthalmol Vis Sci 2015; 56(11): 6646-6653.

11 Bahrami H, Melia M, Dagnelie G. Lutein supplementation in retinitis pigmentosa : PC-based vision assessment in a randomized double-masked placebo-controlled. BCM Ophthalmol 2006; 6: 23.

12 Berson EL, Rosner B, Sandberg MA, Hayes KC, Nicholson BW, Weigel-DiFranco $C$ et al. A randomized trial of vitamin A and vitamin E supplementation for retinitis pigmentosa. Arch Ophthalmol 1993; 111(6): 761-772.

13 Berson EL, Rosner B, Sandberg MA, Weigel-DiFranco C, Brockhurst RJ, Hayes KC et al. Clinical trial of lutein in patients with retinitis pigmentosa receiving vitamin A. Arch Ophthalmol 2010; 128(4): 403-411.

14 Berson EL, Rosner B, Sandberg MA, Weigel-difranco C, Moser A. Clinical trial of docosahexaenoic acid in patients with retinitis pigmentosa receiving vitamin A treatment. Arch Ophthalmol 2004; 122(9): 1306-1314.

15 Berson EL, Rosner B, Sandberg MA, Weigel-difranco C, Moser A. Further evaluation of docosahexaenoic acid in patients with retinitis pigmentosa receiving vitamin A treatment: subgroup analyses. Arch Ophthalmol 2004; 122(9): 1306-1314.

16 Hoffman DR, Locke KG, Wheaton DH, Fish GE, Spencer R, Birch DG. A randomized, placebo-controlled clinical trial of docosahexaenoic acid supplementation for X-linked retinitis pigmentosa. Am J Ophthalmol 2004; 137(4): 704-718.

17 Hughbanks-Wheaton DK, Birch DG, Fish GE, Spencer R, Pearson NS, Takacs A et al. Safety assessment of docosahexaenoic acid in X-linked retinitis pigmentosa: the 
4-year DHAX trial. Invest Ophthalmol Vis Sci 2014; 55(8): 4958-4966.

18 Lee TKM, Clandinin MT, Hébert M, MacDonald IM. Effect of docosahexaenoic acid supplementation on the macular function of patients with Best vitelliform macular dystrophy: randomized clinical trial. Can J Ophthalmol 2010; 45(5): 514-519.

19 Rotenstreich Y, Belkin M, Sadetzki S, Chetrit A, FermanAttar G, Sher I et al. Treatment with 9-cis $\beta$-carotene-rich powder in patients with retinitis pigmentosa: a randomized crossover trial. JAMA Ophthalmol 2013; 131(8): 985-992.

20 Sibulesky L, Pronczuk A, Weigel-difranco C, Rosner B, Berson EL. Safety of $<7500$ RE ( $<25000$ IU) vitamin A daily in adults with retinitis pigmentosa. Am J Clin Nutr 1999; 69(4): 656-663.

21 Wheaton DH, Hoffman DR, Locke KG, Watkins RB, Birch DG. Biological safety assessment of docosahexaenoic acid supplementation in a randomized clinical trial for X-linked retinitis pigmentosa. Arch Ophthalmol 2003; 121(9): 1269-1278.

22 Chowers I, Banin E, Merin S, Cooper M, Granot E. Longterm assessment of combined vitamin $\mathrm{A}$ and $\mathrm{E}$ treatment for the prevention of retinal degeneration in abetalipoproteinaemia and hypobetalipo-proteinaemia patients. Eye 2001; 15(Pt 4): 525-530.

23 Aleman TS, Cideciyan AV, Windsor EA, Schwartz SB, Swider M, Chico JD et al. Macular pigment and lutein supplementation in ABCA4-associated retinal degenerations. Invest Ophthalmol Vis Sci 2007; 48(3): 1319-1329.

24 Sipilä I, Rapola J, Simell O. Supplementary creatine as a treatment for gyrate atrophy of the choroid and retina. N Engl J Med 1981; 304(15): 867-870.

25 Peltola K, Heinonen OJ, Näntö-Salonen K, Pulkki K, Simell O. Oral lysine feeding in gyrate atrophy with hyperornithinaemia - a pilot study. J Inherit Metab Dis 2000; 23(4): 305-307.

26 Rotenstreich Y, Harats D, Shaish A, Pras E, Belkin M. Treatment of a retinal dystrophy, fundus albipunctatus, with oral 9-cis-\{beta\}-carotene. Br J Ophthalmol. 2010; 94(5): 616-621.
27 Salem NJ, Litman B, Kim H, Gawrisch K. Mechanisms of action of docosahexaenoic acid in the nervous system. Lipid 2001; 36(9): 945-959.

28 Giusto NM, Pasquaré SJ, Salvador GA, Castagnet PI, Roque ME, Ilincheta de Boschero MG. Lipid metabolism in vertebrate retinal rod outer segments. Prog Lipid Res 2000; 39(4): 315-391.

29 Schalch W. Carotenoids in the retina-a review of their possible role in preventing or limiting damage caused by light and oxygen. EXS 1992; 62: 280-298.

30 Massof RW, Finkelstein D. Supplemental vitamin A retards loss of ERG amplitude in retinitis pigmentosa. Arch Ophthalmol 1993; 111(6): 751-754.

31 Massof RW, Fishman GA. How strong is the evidence that nutritional supplements slow the progression of retinitis pigmentosa? Arch Ophthalmol 2010; 128(4): 493-495.

32 Dagnelie G, Melia B, Sunness J. Lutein supplementation in RP: Vision measures in the clinic. Invest Ophthalmol Vis Sci 2003; 44: 780.

33 Druesne-Pecollo N, Latino-Martel P, Norat T, Barrandon E, Bertrais S, Galan P et al. Beta-carotene supplementation and cancer risk: a systematic review and metaanalysis of randomized controlled trials. Int J Cancer 2010; 127: 172-184.

34 Chen J, Wall M. Epidemiology and risk factors for idiopathic intracranial hypertension. Int Ophthalmol Clin 2014; 54(1): $1-11$.

35 Warner JE, Larson AJ, Bhosale P, Digre KB, Henley C, Alder SC et al. Retinol-binding protein and retinol analysis in cerebrospinal fluid and serum of patients with and without idiopathic intracranial hypertension. J Neuroophthalmol 2007; 27(4): 258-262.

36 Geubel A, De Galocsy C, Alves N, Rahier J, Dive C. Liver damage caused by therapeutic vitamin A administration: estimate of dose-related toxicity in 41 cases. Gastroenterology 1991; 100(6): 1701-1709.

37 Radu RA, Yuan Q, Hu J, Peng JH, Lloyd M, Nusinowitz S et al. Accelerated accumulation of lipofuscin pigments in the RPE of a mouse model for ABCA4-mediated retinal dystrophies following Vitamin A supplementation. Invest Ophthalmol Vis Sci 2008; 49(9): 3821-3829. 